Dr ALAN COCKER is former Head of the School of Communications at Auckland University of Technology.

\section{A thoughtful approach to teaching media}

Re-inventing the Media, by Graeme Turner. London: Routledge. 2015. 158 pages. ISBN 978-1-138-02070-2

\section{A} S A member of a School of Communication Studies seeking to refresh its curricula, the publication of Graeme Turner's book Re-Inventing the Media is very timely. According to the publishers, Turner 'takes on the task of rethinking how media studies approaches the whole of the contemporary mediascape.' This statement should not lead the reader to expect that Turner is arguing for a root and branch overturning of how we approach and teach the media. Instead, it can be argued that this is rather a sober 're-think' that seeks to address both the elements of change and continuity in teaching communication or media studies today.

In his final chapter Turner addresses what an updated curriculum could look like. He states that its content might not look radically different from what we tend to encounter now. What would be different, in his view, is that it would have significantly different intentions and thus different organising principles from what often occurs today. Turner is particularly

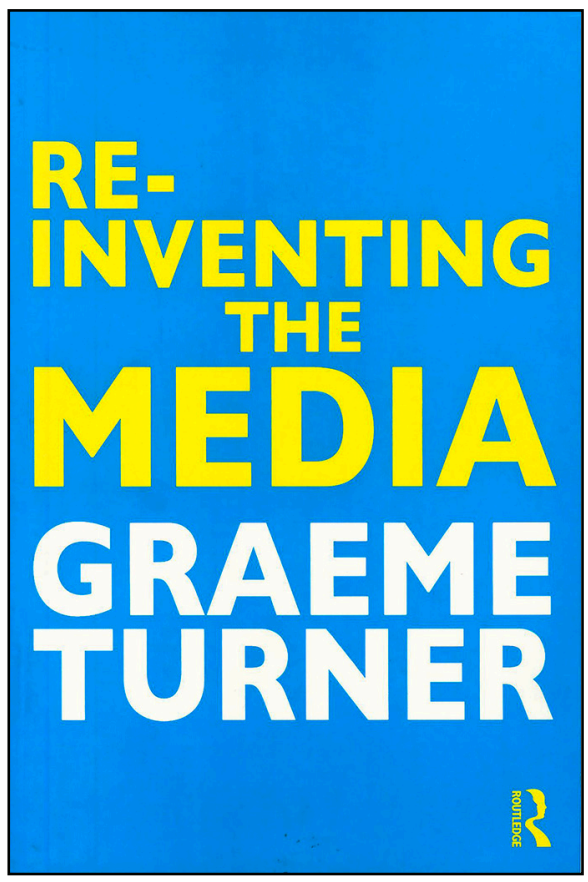

concerned by a trend, encouraged by industry hype about 'new media', to divide the media studies curriculum into two. On the one hand there are courses or programmes on, for example, digital media or new media studies. On the other there is the rump of so-called traditional media studies. He believes this division works against the key objective of 'finding an inclusive and comprehensive framework within which to place the study and analysis of the contemporary media' (p. 14).

In Turner's view the bifurcation of media studies in this manner does not reflect a division in the various media industries, which usually embrace more than one platform. Nor does it reflect audience behaviour which is now largely platform-agnostic and it does not reflect media content, which is 
rarely platform-specific in its distribution. If the various strands of the media are not pulled together and treated as an inclusive whole, there is 'the danger of effectively relegating the analysis of media power to the status of a secondorder issue'. (p. 124).

In an inclusive approach, students may well be trained in particular media, but Turner stresses that our academic purpose as teachers has to be related to the media's fundamental political, cultural and social importance and our core requirement to examine and understand its influence and power. Thus he argues that first-level courses should focus on large-scale and crossplatform issues that influence the structure of all media forms. The argument is for communication or media degrees to start with the big picture, at least in their year one offerings, with the dual objectives of first, understanding what the media does, how it works, and in whose interests; and second, how we make use of the media and to what effect.

Informing this broad, inclusive approach would be an extensively revised and updated content which reflects the transformation of what Turner calls the media manifold. This is covered in the chapters 'Rethinking Media Theory', which covers how we have to adjust our theoretical perspective to account for the decline of the mass media paradigm and 'Rethinking Media Regulation', which outlines the need for revising and adjusting our regulations to account for the impacts of globalisation, new and social media. Other chapters address the restructuring of relations between the state and media, the need to recognise and investigate the diversity of media systems around the world, the need to acknowledge the role of celebrity in contemporary media and account for the connection between the pervasiveness of commercialism and the prioritisation of entertainment over information and news.

Turner concludes that if we seek to understand these changes, critically assess their implications and reintegrate approaches to media studies into a critical, coherent and inclusive whole, then we may be able to claim that our teaching field has renewed itself and is fit for purpose. To Turner's credit, this book outlines a rational and thoughtful approach to tackling the fraught task of revising what and how we teach media and communication studies. 